\title{
Androgen-regulated metabolism and biosynthesis in prostate cancer
}

\author{
Stefan J Barfeld', Harri M Itkonen', Alfonso Urbanucci ${ }^{1}$ and lan G Mills ${ }^{1,2,3}$ \\ ${ }^{1}$ Prostate Cancer Research Group, Centre for Molecular Medicine Norway (NCMM), Nordic EMBL Partnership, \\ University of Oslo and Oslo University Hospital, N-0318 Oslo, Norway \\ ${ }^{2}$ Department of Cancer Prevention, Institute of Cancer Research, and ${ }^{3}$ Department of Urology, \\ Oslo University Hospital, N-0424 Oslo, Norway
}

Correspondence

should be addressed

to I G Mills

Email

ian.mills@ncmm.uio.no

\begin{abstract}
Metabolic changes are a well-described hallmark of cancer and are responses to changes in the activity of diverse oncogenes and tumour suppressors. For example, steroid hormone biosynthesis is intimately associated with changes in lipid metabolism and represents a therapeutic intervention point in the treatment of prostate cancer (PCa). Both prostate gland development and tumorigenesis rely on the activity of a steroid hormone receptor family member, the androgen receptor (AR). Recent studies have sought to define the biological effect of the AR on PCa by defining the whole-genome binding sites and gene networks that are regulated by the AR. These studies have provided the first systematic evidence that the AR influences metabolism and biosynthesis at key regulatory steps within pathways that have also been defined as points of influence for other oncogenes, including c-Myc, p53 and hypoxia-inducible factor $1 \alpha$, in other cancers. The success of interfering with these pathways in a therapeutic setting will, however, hinge on our ability to manage the concomitant stress and survival responses induced by such treatments and to define appropriate therapeutic windows.
\end{abstract}

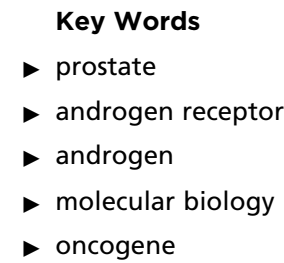

Endocrine-Related Cancer (2014) 21, T57-T66

\section{Introduction: the Warburg effect and cancer metabolism}

In 1927, Otto Warburg discovered increased lactate production as a common denominator in various cancer cells, naming this the 'Warburg effect'. He speculated that this was triggered by an unidentified mitochondrial defect and labelled it 'the cause for cancer' (Warburg et al. 1927). Increased lactate production is now accepted as a prime example of metabolic reprogramming and an emerging hallmark of cancer cells (Hanahan \& Weinberg 2011). In order to understand the significance of this metabolic change in cancer cells, one needs to go back to the basics of biochemistry, to one of the oldest and best conserved metabolic pathways among species - glycolysis, the breakdown of glucose to pyruvate.

Interestingly, proliferating cells (e.g. stem or cancer cells) produce lactate to equalize their electron balance rather than utilizing oxidative phosphorylation, even under aerobic conditions. This is particularly intriguing because the net energy production is significantly lower (2 vs 38 ATP in complete oxidative phosphorylation through the citric acid cycle and electron transport chain). Thus, a lot of potential energy seems to get wasted. However, aerobic glycolysis appears to be advantageous for proliferative active cells - why? It is thought that nutrient availability in proliferative tissue is not a limiting factor, thereby eliminating the selective pressure for an efficient utilization of available energy resources. Instead, the ability to create as much biomass as fast as possible in order to proliferate quickly and efficiently might be the deciding factor while controlling metabolism in those cells. 
A higher metabolic net-rate channels more glucose through glycolysis and yields more intermediates for various anabolic processes, thereby increasing the rate of biomass production and speeding up the cell cycle. In fact, about $10 \%$ of the glucose utilized in glycolysis in proliferating cells is being used for anabolic pathways upstream of pyruvate (Vander Heiden et al. 2009). Examples of these pathways include the pentose-phosphate pathway as well as amino acid, lipid and nucleotide synthesis, all processes yielding building blocks required to sustain effective cell proliferation.

A second metabolic hallmark of cancer cells is an elevated uptake and consumption of glutamine, sometimes to a degree where glutamine becomes an essential substance for maintaining proliferation (Hensley et al. 2013). This increased glutaminolysis provides the cells with carbon backbones, nitrogen and reducing equivalents $(\mathrm{NADPH})$, all necessary building blocks for anabolic processes and therefore proliferation. For example, glutaminolysis feeds into the citric acid cycle via 2-oxoglutarate to keep the cycle up and running. This is crucial as its intermediates are constantly being channelled into anabolic pathways, such as lipid biosynthesis (acetyl-CoA) or the synthesis of non-essential amino acids (e.g. oxaloacetate and 2-oxoglutarate) (DeBerardinis et al. 2008). It is therefore not surprising that metabolic adaptations have been reported in various human cancers (Hsu \& Sabatini 2008).

\section{Metabolic status of the prostate gland and cancer predisposition}

The prostate gland is principally responsible for secreting factors that enhance sperm viability during reproduction. Both the development of the prostate gland and maintenance of these secretory functions require androgens and the androgen receptor (AR; Pritchard \& Nelson 2008). While the AR is now known to be expressed in many other cell types in the body, luminal epithelial cells in the prostate gland express particularly high levels (Bonkhoff $\&$ Remberger 1993). These are the specialist secretory cells that release prostate-specific proteins, including kallikreins, such as prostate-specific antigen (Cohen et al. 1998). Furthermore, the prostate gland also has a specialized metabolic role as a secretor of citrate, and citrate secretion falls upon progression to metastasis (Marberger et al. 1962). Apparently, high concentrations of secreted citrate play an important role in maintaining sperm viability through calcium chelation and as an energy source (Ford \& Harrison 1984). In order to function as a net secretor of citrate, the normal metabolic activity of luminal epithelial cells is altered so that the tricarboxylic acid (TCA) cycle does not function efficiently and citrate accumulates for secretion (Costello \& Franklin 1981). This requires elevated zinc concentrations within prostate cells and concomitant inhibition of cis-aconitase within the TCA cycle (Singh et al. 2006). The impaired efficiency of the TCA cycle in untransformed cells is predicted to mean that basal energy metabolism in the prostate gland is more glycolytic, or Warburg-like, than in other tissues (Fig. 1). Overall, therefore, even in the untransformed prostate, the AR helps to drive the expression of metabolic enzymes and secreted proteins associated with biomass production, although for secretion rather than tumorigenesis (Heemers et al. 2003).

\section{Defining clinically relevant AR target genes and pathways}

AR target genes can be classified based on the transcripts and proteins that are hormone responsive. The development of chromatin immunoprecipitation (ChIP) to enrich AR bound to DNA has allowed the presence of AR binding sites within regulatory regions flanking these genes to be used as an additional classifier (Lamont \& Tindall 2010, Massie \& Mills 2012). However, directly associating a binding site with a given gene and its expression is very challenging because genomic DNA can loop and form higher order structures (Wu et al. 2011). This means that AR binding events can act in cis, i.e. exert proximal regulatory effects on nearby genes, or in trans, i.e. exhibit distal associations with genes many hundreds of kilobases or megabases away from the binding site or indeed on other chromosomes. Consequently, detailed classification criteria for AR target genes vary somewhat from studyto-study but typically associations between AR binding sites and genes are inferred over distances of up to $100 \mathrm{~kb}$. The overall conclusion is that many genes required for glucose consumption, lipid turnover and biomass production/anabolic metabolism are androgen-dependent and regulated by the AR in both untransformed prostate cells and at least in localized prostate cancer (PCa; Massie et al. 2011, Sharma et al. 2013). In untransformed cells, this is an important feature for maintaining high rates of protein synthesis and glycosylation to sustain the secretory function of the prostate gland. Strikingly, metaanalyses of expression array data from localized PCa consistently report significant changes in genes associated with lipid-metabolizing pathways, glycosylation and calcium signalling (Gorlov et al. 2009). Some genes, for

Published by Bioscientifica Ltd. 


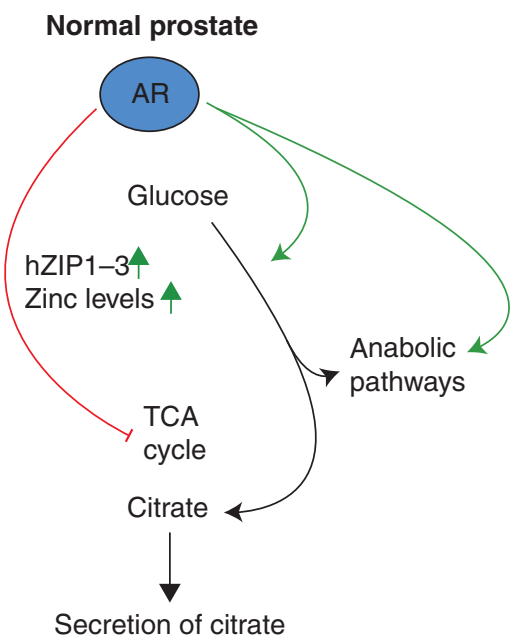

\section{Figure 1}

Metabolic status of the prostate gland during disease progression. The prostate gland requires high rates of anabolic metabolism and impaired mitochondrial metabolism to function as a secretory organ and net secretor of citrate. High expression of members of the zinc transporter (hZIP) family helps to maintain elevated intracellular zinc concentrations, leading to inhibition of cis-aconitase in the TCA cycle and subsequent accumulation of citrate. Citrate is then secreted and helps to maintain sperm viability through calcium chelation and as an energy source for motility. On the other hand, malignant transformation of the prostate gland is characterized by a reduction of citrate secretion through decreased expression of hZIP transporters and concomitant reduction in intracellular zinc levels. In addition, the expression of antioxidant enzymes such as

example fatty acid synthase, are both PCa biomarkers overexpressed in early-stage disease but also rather abundantly expressed in untransformed cells, and androgen-regulated in both settings (Swinnen, et al. 1997, Kusakabe et al. 2000, Migita et al. 2009). $\alpha$-Methylacyl-CoA racemase, in contrast, is more cancer-specific. While its function remains to be precisely defined, in $\mathrm{PCa}$, it has been implicated in the $\beta$-oxidation of fatty acids and associated with peroxisome function in other settings (Rubin et al. 2002, Lloyd et al. 2008). Changes in the expression of lipid-metabolizing enzymes therefore represent a good example of an early hallmark of PCa essentially dysregulating an established feature of AR-dependent gene expression in the prostate gland. At present, we do not know the definitive trigger for dysregulation but family history (genetics), ageing and possibly diet and oxidative stress may play important roles in perturbing AR activity.

Gene silencing is also an important feature of PCa tumorigenesis and contributes to metabolic reprogramming. Silencing of the expression of zinc transporters (hZIP1-3) is an early event in the development of PCa and these proteins are required to maintain high zinc

\section{Transformed prostate}

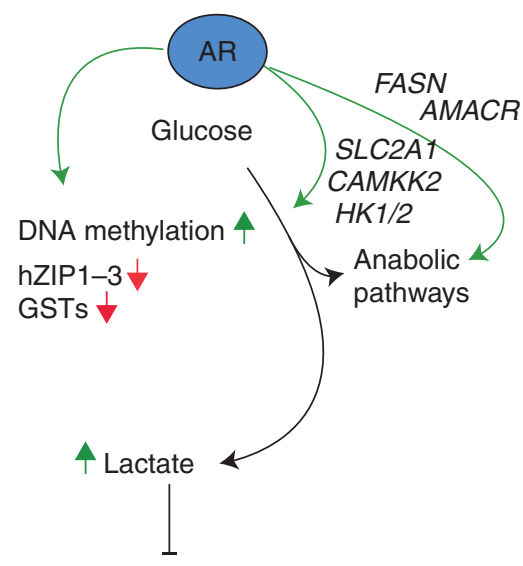

Secretion of citrate

glutathione S-transferases (GST) is reduced through promoter hypermethylation. Genes involved in glycolysis (e.g. GLUT1 (SLC2A1), CAMKK2 and $H K 1 / 2$ ) and lipid metabolism (e.g. FASN and AMACR) are known to be upregulated early during disease initiation, leading to disease-associated amplification or dysregulation of established AR-driven pathways required to sustain secretory activity in untransformed prostate luminal epithelial cells. hZIP family: SLC39A1-3, solute carrier family 39 (zinc transporters); GST, members of the glutathione $S$-transferase family; SLC2A1, solute carrier family 2 (facilitated glucose transporter), member 1; CAMKK2, calcium/calmodulin-dependent protein kinase kinase $2 ; \mathrm{HK} 1 / 2$, hexokinase 1 and 2; FASN, fatty acid synthase; AMACR, $\alpha$-methylacyl-CoA racemase.

concentrations in prostate tissue and suppress cis-aconitase and presumably mitochondrial activity (Fig. 1; Franklin et al. 2005, Desouki et al. 2007). Other early changes involve promoter hypermethylation and repressed transcription of antioxidant enzymes of the glutathione $S$-transferase family (Tokumaru et al. 2004). Although never examined collectively in a single cohort, this implies that, in contrast to the strict definition of the Warburg effect as aerobic glycolysis, both glycolytic and mitochondrial activity may be enhanced in localized PCa. However, exploiting these metabolic changes for the development of cancer biomarkers and therapeutics is not trivial owing to the complex interplay within metabolic pathways.

This complexity is illustrated by an enzyme, calcium/ calmodulin-dependent kinase kinase 2 (CAMKK2), which was recently reported to be an AR target gene and highly expressed at the protein and transcript levels in PCa. At the transcript level, CAMKK2 appears to be more significantly expressed in PCa than in cancers at other organ sites based on the data available within Oncomine and other clinical databases (Massie et al. 2011). In untransformed tissues, 
CAMKK2 is predominantly expressed in the CNS (Anderson et al. 2008). Inhibitors of CAMKK2 were initially developed to treat obesity and proved effective in mouse models (Tokumitsu et al. 2002, Anderson et al. 2008). Of the small number of CAMKK2 substrates identified, AMP-regulated kinase (AMPK) was the best characterized and has so far provided the predominant reference point to explain the functional effects of CAMKK2 in both the hypothalamus and PCa cells (Hawley et al. 2005, Massie et al. 2011). Interestingly, in the hypothalamus, the CAMKK2-AMPK axis mediates the response to the hunger-stimulating hormone ghrelin, thereby affecting whole-body energy metabolism (Anderson et al. 2008), while in PCa cells, CAMKK2dependent activation of AMPK leads to increased activity of phosphofructokinase, a rate-limiting enzyme in glycolysis. This promotes glucose consumption and lactate production (Massie et al. 2011). Intriguingly, AMPK is also activated in untransformed cells under conditions of metabolic stress/ATP deprivation. In this context, this enhances glycolysis and catabolic metabolism while inhibiting anabolic metabolism, thus rebalancing metabolic networks towards net energy production (Towler \& Hardie 2007). In contrast, in cancer cells, activation of AMPK enhances glycolysis but does not always inhibit anabolic metabolism (Fig. 2). Explaining this paradox is proving a major challenge, but there are indications that certain AMPK substrates that negatively regulate protein synthesis are expressed as inactive androgen-regulated variants, for example tuberous sclerosis 2 (Wu et al. 2010, Rajan et al. 2011).

The availability of other metabolic inhibitors, such as metformin, which is used to treat type 2 diabetes and enhances AMPK activity through various mechanisms including inhibition of complex 1 of the mitochondrial respiratory chain, has increased the interest in defining patient cohorts that will benefit most from these drugs (Margel et al. 2013). However, responses to these drugs may vary and in part reflect differences in metabolic activity in different regions of the same tumour,

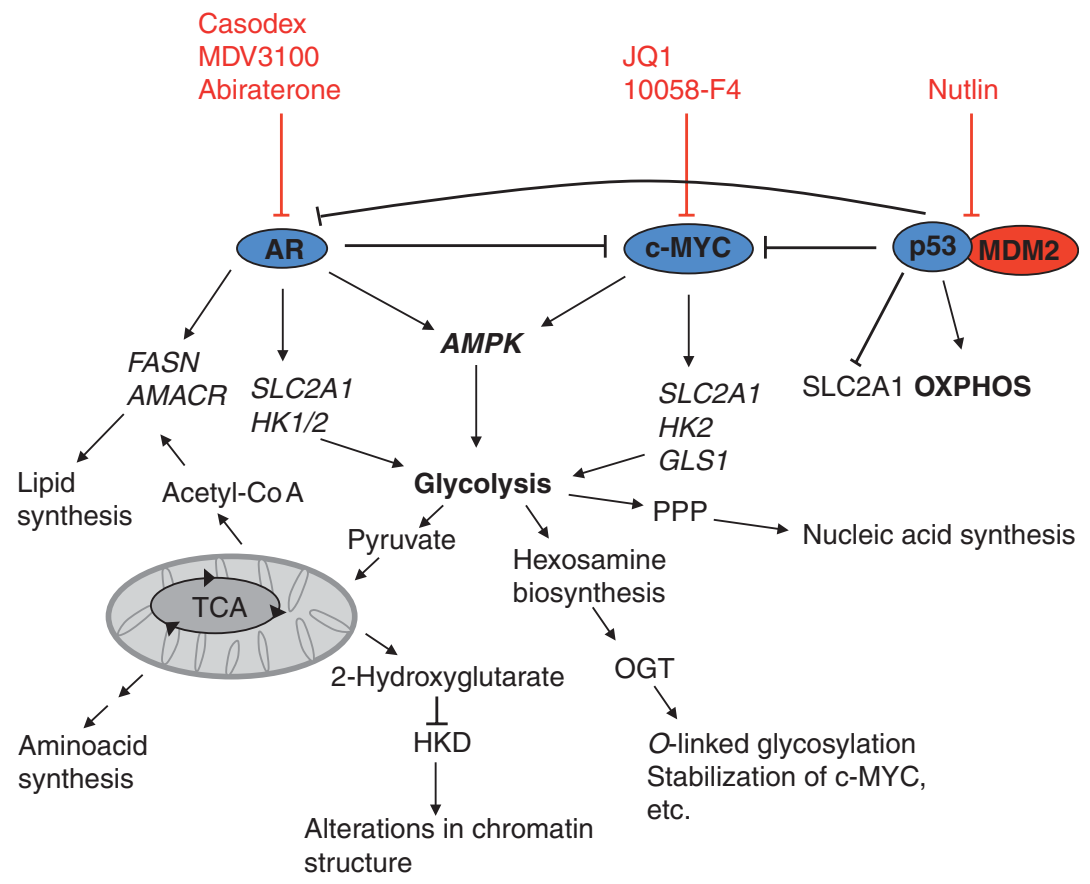

Figure 2

Androgen receptor (AR) and MYC regulate convergent pathways in prostate cancer (PCa). AR is the major drug target in the PCa and its activity can be inhibited with anti-androgens (e.g. casodex, MDV3100) or steroid biosynthesis inhibitors such as abiraterone. Steroid-activated AR decreases the levels of MYC, a major oncogene in a number of cancers. MYC can also be targeted with small molecules such as JQ1 and 10058-F4. Both MYC and the AR can activate AMPK, enhance glycolysis and support funnelling of TCA cycle metabolites to anabolic pathways. Tumour suppressor $\mathrm{p} 53$ inhibits both
AR and MYC and supports oxidative phosphorylation at the expense of anabolic metabolism. Drugs that stabilize p53 include the Nutlins that inhibit interaction between $\mathrm{p} 53$ and MDM2. FASN, fatty acid synthase; AMACR, $\alpha$-methylacyl-CoA racemase; HK1/2, hexokinase 1/2; KDM, histone lysine demethylase; AMPK, AMP-activated protein kinase; GLS1, glutaminase 1; MDM2, E3 ubiquitin-protein ligase Mdm2; SLC2A1, solute carrier family 2 (facilitated glucose transporter), member 1; TCA, tricarboxylic acid cycle; PPP, pentose-phosphate pathway; OXPHOS, oxidative phosphorylation. http://erc.endocrinology-journals.org DOI: 10.1530/ERC-13-0515
(C) 2014 Society for Endocrinology Printed in Great Britain
Published by Bioscientifica Ltd 
particularly in PCa, which is known be a multifocal, heterogeneous disease. Tackling these issues systematically and in a timely manner will require new partnerships between industry and academia.

\section{Other oncogenic regulators of metabolism}

Although not the main focus of this review, it is useful to reflect briefly on the fact that PCa is not driven by a single transcription factor despite the heavy focus on the AR. Cell cycle progression and metabolism are convergently regulated by multiple oncogenic signalling events and transcription factors, including c-Myc, which is overexpressed and predictive of poor prognosis in a subset of cases (Hawksworth et al. 2010). Other examples include hypoxia-inducible factor $1 \alpha$ (HIF1A), which is associated with PCa metastasis (Ranasinghe et al. 2013). In addition, p53 mutations, PTEN loss and enhanced PI3-kinase signalling are common events in advanced PCa (Elsberger et al. 2010, Grasso et al. 2012). All these are wellcharacterized regulators of metabolic changes, although so far more extensively studied in other cancers. Metabolic changes should therefore be viewed as central to cancer biology, and as AR-targeted drugs improve, we must be aware that we are applying selection pressures, which in part may enhance the contribution from other pathways to maintenance of cancer metabolism (Fig. 2; Carver et al. 2011, Thompson 2011).

c-MYC contributes to metabolic adaptations, especially the Warburg effect, at many of the same steps in metabolic pathways as the AR. The expression of the glucose transporter GLUT1 and various enzymes of the (oxidative) glycolytic pathway (hexokinase 2, phosphofructokinase, enolase 1 and lactate dehydrogenase A) have been reported to be under direct control of c-MYC in various cancers (Shim et al. 1997, Osthus et al. 2000, Kim et al. 2004). Interestingly, many of these effects are exerted in cooperation with HIF1 (Gordan et al. 2007). Furthermore, recent results have indicated that c-MYC is also responsible for driving enhanced glutaminolysis in cancer cells, thereby maintaining mitochondrial function and oxidative phospshorylation. Glutamine transporters and mitochondrial glutaminase, GLS1, appear to be directly or indirectly (via miRNAs) regulated by c-MYC (Wise et al. 2008, Gao et al. 2009). Intriguingly, many cancers driven by c-MYC amplification or overexpression seem to be highly dependent on glutamine, and glutamine deprivation leads to rapid exhaustion of citric acid cycle intermediates and apoptosis (Yuneva et al. 2007). c-MYC may also play a role in more global metabolic reprogramming, such as redirecting citric acid cycle intermediates into other anabolic pathways like nucleic acid or amino acid synthesis with clear parallels to the reprogramming effects recently attributed to the AR (O'Connell et al. 2003). Potentially, the balance between oncogenic transcription factors might be a crucial factor here as androgen stimulation inhibits the expression of c-MYC in PCa cells (Kokontis et al. 1994).

Loss of WT p53 function is one the most common mutations in virtually all human cancers (Kandoth et al. 2013), leading to loss of cell cycle and apoptotic control as well as chromosomal instability (Hollstein et al. 1991). It is usually a loss of one allele and missense mutation in the second that cause the deficit in p53 WT activity (Kastan \& Berkovich 2007). In contrast, gain-of-function mutations in p53 can confer oncogenic properties, promoting resistance to apoptosis upon treatment with chemotherapeutics (Blandino et al. 1999). WT p53 can act as a tumour suppressor and is able to revert many of the metabolic effects on, e.g. glycolytic flux exerted by c-MYC and HIF1 by suppressing the expression of genes associated with glucose uptake and the pentose phosphate shunt pathway (Fig. 2; Jiang et al. 2011, Zawacka-Pankau et al. 2011).

In addition, p53 controls glutamine metabolism through activation of GLS2, a mitochondrial glutaminase (Hu et al. 2010). This seems contradictory at first because c-MYC is also capable of interfering with glutamine metabolism, albeit through controlling the expression of the mitochondrial glutaminase GLS1 (Yuneva et al. 2012). However, while activation of glutaminolysis through GLS1 diverts TCA cycle intermediates into anabolic pathways, p53-mediated activation of GLS2 promotes ATP production through oxidative phosphorylation (Vousden 2010). The crosstalk between the AR and p53 has not been intensively studied but reports indicate that activation of p53 is able to inhibit AR activity (Cronauer et al. 2004), while loss of p53 promotes MYC-dependent PCa (Thompson et al. 1995). It will be important to characterize the effects of mutated p53 on PCa cells, particularly in metastatic disease.

\section{Metabolic feedback effects and stress responses}

Changes in metabolic flux impose stresses on cells. For example, elevated anabolic metabolism and protein synthesis particularly increase the flux through the endoplasmic reticulum (ER), where newly synthesized proteins are folded and post-translationally modified. ER stress is often associated with increased ribosome

Published by Bioscientifica Ltd. 
biogenesis and elevated rates of splicing and transcript turnover. As rate-limiting organelles in protein and transcript processing the ER and the nucleolus, are significant sensors and responders to the metabolic stress (Bravo et al. 2013, Grummt 2013). The ER plays a role as a principal site for protein folding and the nucleolus in the processing and assembly of ribonucleoprotein complexes to sustain protein synthesis and splicing. Thus, the genes required for the assembly of these structures and for stress signalling would be expected to be coordinately regulated by the AR and also by other oncogenic transcription factors. Strikingly, the AR has indeed been reported to activate the ER stress response (Segawa et al. 2002). In addition, early studies on rats showed that castration leads to the progressive disorganization of the nucleolus in prostate cells, which can be reversed by testosterone injection (Dahl 1976). Further results indicate that AR can directly enhance the transcription of rRNA (Mainwaring \& Derry 1983, Li et al. 2013).

\section{ER and the unfolded protein response}

The imposition of metabolic stress on cells triggers a series of signalling events in the cell known as the unfolded protein response (UPR). In mammalian cells, there are three arms to this response, each culminating in the processing and activation of a transcription factor (ATF4, ATF6 and XBP1; Gardner et al. 2013). Target genes for these transcription factors include heat-shock proteins with chaperone functions and autophagy genes. During autophagy, misfolded proteins and organelles become enveloped in a membrane structure called the autophagosome and ultimately degraded in the lysosomes (Suh et al. 2012). This process enables cells to maintain quality control and also to produce energy under nutrientdeficient conditions. In addition, the ER-associated degradation pathway can be activated partly by changes in gene expression. This pathway involves active extrusion of misfolded proteins from the ER into the cytoplasm through a pore complex in the ER membrane (Sec61 complex; Brodsky 2012). Once extruded, misfolded proteins can then be polyubiquitinylated prior to proteasomal degradation (Brodsky 2012).

Recently, we employed ChIP and expression profiling on human tumours to identify AR target genes and binding sites associated with castration-resistant $\mathrm{PCa}$ (CRPC; Sharma et al. 2013). We identified around 2500 AR binding sites in CRPC tissue, of which around half were found only in tissue but not in cell lines, indicating context dependency (Sharma etal. 2013). Additionally, gene expression profiling identified a 150-gene signature associated with CRPC, which were defined as genes that were initially androgen-responsive, subsequently repressed by androgen deprivation and ultimately reexpressed/highly expressed in a xenograft model of CRPC and in addition were also highly expressed in human CRPC (Sharma et al. 2013). From this work, it appears that the XBP1 arm of the UPR is androgen-regulated with a key kinase/endonuclease in the pathway, IRE1, being actively induced by androgen treatment in cell lines and XBP1 itself forming part of the 150-gene signature (Sharma et al. 2013). Strikingly, refining this list by linking it tightly to AR binding sites and poor prognosis produced a core signature of 16 genes associated with poor prognosis, which still included ER genes linked to the UPR (Sharma et al. 2013). Interestingly, the gene signature included anterior gradient 2 , which is both an XBP1 target gene that represses inflammatory bowel disease and has previously been reported to be a prognostic marker in PCa (Higa et al. 2011, Mimura et al. 2012, Wayner et al. 2012).

More work is needed to determine whether this pathway might be an adaptive response to treatment and/or a necessary adjunct to metabolic stresses imposed by aberrant AR activity in localized disease. Interestingly, a regulator of the UPR, $78 \mathrm{kDa}$ glucose-regulated protein, has been reported to be a biomarker for localized PCa. Hence, it may be that UPR is an important adaptive response in progression to late-stage disease and/or upon the imposition of stresses through treatment (Tan et al. 2011). Evidence has recently emerged from other cancers for the importance of UPR activation in carcinogenesis. In lymphoma, activation of the ATF4 arm of the UPR supports c-Myc-dependent tumorigenesis by driving the expression of genes necessary for the assembly of autophagosomes (Hart et al. 2012).

\section{Metabolic feedback through changes in metabolite pools}

Changes in metabolic flux may also alter the size of metabolite pools to sustain the post-translational modification of proteins. As discussed earlier, metabolic reprogramming is an important feature of $\mathrm{PCa}$, and furthermore, metabolic pathways are known to provide the adducts to sustain acetylation, methylation and glycosylation. Consequently, it is interesting to consider whether changes in the transcription of metabolic enzymes may in turn affect the stability of transcription factors and/or chromatin accessibility by affecting these

Published by Bioscientifica Ltd. 
modifications. Recently, the enzymes in the hexosamine biosynthesis pathway were shown to be androgen regulated and overexpressed in PCa patients (Itkonen et al. 2013). Strikingly, this pathway is sustained by metabolites sourced from the major metabolic processes in the cell (glucose from glycolysis, glutamine from amino acid metabolism, acetyl-CoA from lipids and carbohydrate turnover and UTP from nucleotide metabolism; Hanover et al. 2010, Slawson et al. 2010). The end-product is an aminosugar conjugate called UDP- $\mathrm{N}$-acetylglucosamine (UDP-GlcNAc), which serves as a substrate for different protein-modifying enzymes. For example, O-GlcNAc transferase can add a monosaccharide O-GlcNAc modification to serine/threonine residues throughout the cell. Alternatively, UDP-GlcNAc can also be used for more complex $N$-linked glycosylation in the ER. As an example, $O$-GlcNAc modification of c-Myc stabilizes the protein by reducing proteasomal degradation rates (Chou et al. $1995 a, b)$. De-convoluting the influence of these changes on cancer cells will require proteomic approaches to map modification sites and further development of glycosylation-site-specific antibodies. In contrast, acetylation and methylation are more established post-translational modifications as global changes in histone acetylation and methylation are hallmarks of cancer cells (Plass et al. 2013). Recently, mutations in iso-citrate dehydrogenases (IDH1 and IDH2) were reported, which result in the production of the 'oncometabolite' 2-hydroxyglutarate (Chowdhury et al. 2011). 2-Hydroxyglutarate inhibits 2-oxoglutarate-dependent oxygenases, such as histone lysine demethylases, leading to aberrant histone methylation patterns. Albeit IDH mutations occur at a low frequency in PCa (Ghiam et al. 2012), it is interesting that IDH1 is an androgen-regulated gene and could therefore play a role in a subset of patients. On the other hand, lipid turnover provides a significant source of acetyl groups to a major degree due to the activity of nuclear ATP-citrate lyase (ACLY), an enzyme required for de novo fatty acid synthesis responsible for generating cytosolic acetyl-CoA and oxaloacetate (Zaidi et al. 2012). This enzyme is both an AR target gene and activated by Akt phosphorylation, which is further enhanced by the loss of PTEN in cancer (Berwick et al. 2002, Wellen et al. 2009, Massie et al. 2011). ACLY inhibitors or knockdown of ACLY in turn reduce histone acetylation and tumour growth in xenografts (Hatzivassiliou et al. 2005, Wellen et al. 2009). This raises the intriguing possibility that the transcriptional activity of the AR may be further enhanced by increased histone acetylation and concomitant chromatin opening and enhancer activity.
A further example of regulatory effects on the supply of hydrocarbon adducts in PCa centres on sarcosine, a metabolite in the one-carbon/folate pathway from which methyl groups are generated. Sarcosine is significantly increased in some but not in all PCa cohorts and has been reported to be detectable in urine samples (Sreekumar et al. 2009, Jentzmik et al. 2010, Wagner \& Luka 2011). The enzyme required to synthesize this metabolite is glycine $\mathrm{N}$-methyltransferase (GNMT), an AR target gene in PCa cell lines (Ottaviani et al. 2013). Strikingly, both sarcosine and GNMT have been reported to negatively regulate DNA methyltransferase activity (Wang et al. 2011). Collectively, AR may therefore promote histone acetylation at the expense of DNA methylation in PCa. In contrast, c-Myc is known to increase the expression of other genes in the one-carbon/folate pathway as well as targeting DNA methyltransferases to specific loci (Nikiforov et al. 2002, Brenner et al. 2005). Targeted DNA hypermethylation is, in many cancers, a hallmark of reprogramming associated with cancer progression and resulting in the silencing of candidate tumour suppressors including the glutathione $S$-transferases referred to earlier (Akhavan-Niaki \& Samadani 2013). Consequently, like the UPR, chromatin modifications responding to metabolic flux may partly reflect the relative activity of the AR and other oncogenic transcription factors in PCa.

\section{Future perspectives}

ChIP, sequencing and expression profiling have provided the tools to uncover connections between the AR and metabolic changes in PCa. However, multi-parametric approaches to assess the effects of transcription and signalling on the flux and capacity of metabolic pathways in an integrated manner are still lacking. Arguably, the more progress that is made in affecting the AR using drugs, the more we will select for other oncogenic transcription factors that will sustain cancer metabolism. Consequently, the challenge in targeting cancer metabolism is not to switch it off but rather to tip the balance sufficiently to make a mainstream cytotoxic drug or inhibitor of oncogenic signalling more effective without actively promoting a competing oncogenic process. This is a challenge that can never be entirely met, but if we are able to use glycosylation, acetylation and methylation as surrogate response markers, we may in the future be able to more sensitively assess that balance. As we learn more about the systems biology of cancer metabolism, this will become more achievable and will assist us in repositioning clinically approved drugs developed to treat metabolic diseases to fight PCa.

Published by Bioscientifica Ltd 


\section{Declaration of interest}

The authors declare that there is no conflict of interest that could be perceived as prejudicing the impartiality of the research reported.

\section{Funding}

S J Barfeld is funded by the Norwegian Cancer Society. H M Itkonen is funded by an EU FP7 Marie Curie ITN (Pro-Nest) and by the Finnish Cultural Foundation. A Urbanucci is funded by Molecular Life Sciences, University of Oslo. I G Mills is a visiting scientist at Cancer Research UK and an honorary senior visiting research fellow at the University of Cambridge. The Centre for Molecular Medicine Norway (NCMM) is funded by the Norwegian Research Council, University of Oslo and the Health South East. The group is also funded by grants from the Movember Foundation. This funding support is not dedicated to the themes of this review.

\section{References}

Akhavan-Niaki H \& Samadani AA 2013 DNA methylation and cancer development: molecular mechanism. Cell Biochemistry and Biophysics 67 501-513. (doi:10.1007/s12013-013-9555-2)

Anderson KA, Ribar TJ, Lin F, Noeldner PK, Green MF, Muehlbauer MJ, Witters LA, Kemp BE \& Means AR 2008 Hypothalamic CaMKK2 contributes to the regulation of energy balance. Cell Metabolism $\mathbf{7}$ 377-388. (doi:10.1016/j.cmet.2008.02.011)

Berwick DC, Hers I, Heesom KJ, Moule SK \& Tavare JM 2002 The identification of ATP-citrate lyase as a protein kinase B (Akt) substrate in primary adipocytes. Journal of Biological Chemistry 277 33895-33900. (doi:10.1074/jbc.M204681200)

Blandino G, Levine AJ \& Oren M 1999 Mutant p53 gain of function: differential effects of different p53 mutants on resistance of cultured cells to chemotherapy. Oncogene 18 477-485. (doi:10.1038/sj.onc. 1202314)

Bonkhoff H \& Remberger K 1993 Widespread distribution of nuclear androgen receptors in the basal cell layer of the normal and hyperplastic human prostate. Virchows Archiv. A, Pathological Anatomy and Histopathology 422 35-38. (doi:10.1007/BF01605130)

Bravo R, Parra V, Gatica D, Rodriguez AE, Torrealba N, Paredes F, Wang ZV, Zorzano A, Hill JA, Jaimovich E et al. 2013 Endoplasmic reticulum and the unfolded protein response: dynamics and metabolic integration. International Review of Cell and Molecular Biology $\mathbf{3 0 1}$ 215-290. (doi:10.1016/B978-0-12-407704-1.00005-1)

Brenner C, Deplus R, Didelot C, Loriot A, Vire E, De Smet C, Gutierrez A, Danovi D, Bernard D, Boon T et al. 2005 Myc represses transcription through recruitment of DNA methyltransferase corepressor. EMBO Journal 24 336-346. (doi:10.1038/sj.emboj.7600509)

Brodsky JL 2012 Cleaning up: ER-associated degradation to the rescue. Cell 151 1163-1167. (doi:10.1016/j.cell.2012.11.012)

Carver BS, Chapinski C, Wongvipat J, Hieronymus H, Chen Y, Chandarlapaty S, Arora VK, Le C, Koutcher J, Scher H et al. 2011 Reciprocal feedback regulation of PI3K and androgen receptor signaling in PTEN-deficient prostate cancer. Cancer Cell 19 575-586. (doi:10.1016/j.ccr.2011.04.008)

Chou TY, Dang CV \& Hart GW 1995a Glycosylation of the c-Myc transactivation domain. PNAS 92 4417-4421. (doi:10.1073/ pnas.92.10.4417)

Chou TY, Hart GW \& Dang CV $1995 b$ c-Myc is glycosylated at threonine 58 , a known phosphorylation site and a mutational hot spot in lymphomas. Journal of Biological Chemistry 270 18961-18965. (doi:10.1074/jbc.270.32.18961)

Chowdhury R, Yeoh KK, Tian YM, Hillringhaus L, Bagg EA, Rose NR, Leung IK, Li XS, Woon EC, Yang M et al. 2011 The oncometabolite 2-hydroxyglutarate inhibits histone lysine demethylases. EMBO Reports 12 463-469. (doi:10.1038/embor.2011.43)

Cohen RJ, McNeal JE, Edgar SG, Robertson T \& Dawkins HJ 1998 Characterization of cytoplasmic secretory granules (PSG), in prostatic epithelium and their transformation-induced loss in dysplasia and adenocarcinoma. Human Pathology 29 1488-1494. (doi:10.1016/ S0046-8177(98)90020-X)

Costello LC \& Franklin RB 1981 Aconitase activity, citrate oxidation, and zinc inhibition in rat ventral prostate. Enzyme 26 281-287.

Cronauer MV, Schulz WA, Burchardt T, Ackermann R \& Burchardt M 2004 Inhibition of p53 function diminishes androgen receptor-mediated signaling in prostate cancer cell lines. Oncogene 23 3541-3549. (doi:10.1038/sj.onc.1207346)

Dahl E 1976 The ultrastructure of the accessory sex organs of the male rat. XI Nuclear alterations of prostatic epithelial cells induced by castration. Cell and Tissue Research 171 285-296. (doi:10.1007/BF00224654)

DeBerardinis RJ, Lum JJ, Hatzivassiliou G \& Thompson CB 2008 The biology of cancer: metabolic reprogramming fuels cell growth and proliferation. Cell Metabolism 7 11-20. (doi:10.1016/j.cmet. 2007.10.002)

Desouki MM, Geradts J, Milon B, Franklin RB \& Costello LC 2007 hZip2 and hZip3 zinc transporters are down regulated in human prostate adenocarcinomatous glands. Molecular Cancer 6 37. (doi:10.1186/ 1476-4598-6-37)

Elsberger B, Lankston L, Orange C, Underwood MA \& Edwards J 2010 Expression of hypoxia inducible factor- $1 \alpha$ in matched hormone naive and castrate resistant prostate cancer specimens. Cancer Biomarkers: Section A of Disease Markers 8 1-9. (doi:10.3233/DMA-2011-0805)

Ford WC \& Harrison A 1984 The role of citrate in determining the activity of calcium ions in human semen. International Journal of Andrology 7 198-202. (doi:10.1111/j.1365-2605.1984.tb00777.x)

Franklin RB, Feng P, Milon B, Desouki MM, Singh KK, Kajdacsy-Balla A, Bagasra O \& Costello LC 2005 hZIP1 zinc uptake transporter down regulation and zinc depletion in prostate cancer. Molecular Cancer 432. (doi:10.1186/1476-4598-4-32)

Gao P, Tchernyshyov I, Chang TC, Lee YS, Kita K, Ochi T, Zeller KI, De Marzo AM, Van Eyk JE, Mendell JT et al. 2009 c-Myc suppression of miR-23a/b enhances mitochondrial glutaminase expression and glutamine metabolism. Nature 458 762-765. (doi:10.1038/ nature07823)

Gardner BM, Pincus D, Gotthardt K, Gallagher CM \& Walter P 2013 Endoplasmic reticulum stress sensing in the unfolded protein response. Cold Spring Harbor Perspectives in Biology 5 a013169. (doi:10.1101/ cshperspect.a013169)

Ghiam AF, Cairns RA, Thoms J, Dal Pra A, Ahmed O, Meng A, Mak TW \& Bristow RG 2012 IDH mutation status in prostate cancer. Oncogene $\mathbf{3 1}$ 3826. (doi:10.1038/onc.2011.546)

Gordan JD, Thompson CB \& Simon MC 2007 HIF and c-Myc: sibling rivals for control of cancer cell metabolism and proliferation. Cancer Cell 12 108-113. (doi:10.1016/j.ccr.2007.07.006)

Gorlov IP, Byun J, Gorlova OY, Aparicio AM, Efstathiou E \& Logothetis CJ 2009 Candidate pathways and genes for prostate cancer: a metaanalysis of gene expression data. BMC Medical Genomics 248. (doi:10.1186/1755-8794-2-48)

Grasso CS, Wu YM, Robinson DR, Cao X, Dhanasekaran SM, Khan AP, Quist MJ, Jing X, Lonigro RJ, Brenner JC et al. 2012 The mutational landscape of lethal castration-resistant prostate cancer. Nature $\mathbf{4 8 7}$ 239-243. (doi:10.1038/nature11125)

Grummt I 2013 The nucleolus - guardian of cellular homeostasis and genome integrity. Chromosoma 122 487-497. (doi:10.1007/s00412013-0430-0)

Hanahan D \& Weinberg RA 2011 Hallmarks of cancer: the next generation. Cell 144 646-674. (doi:10.1016/j.cell.2011.02.013)

Hanover JA, Krause MW \& Love DC 2010 The hexosamine signaling pathway: O-GlcNAc cycling in feast or famine. Biochimica et Biophysica Acta 1800 80-95. (doi:10.1016/j.bbagen.2009.07.017) 
Hart LS, Cunningham JT, Datta T, Dey S, Tameire F, Lehman SL, Qiu B, Zhang H, Cerniglia G, Bi M et al. 2012 ER stress-mediated autophagy promotes Myc-dependent transformation and tumor growth. Journal of Clinical Investigation 122 4621-4634. (doi:10.1172/JCI62973)

Hatzivassiliou G, Zhao F, Bauer DE, Andreadis C, Shaw AN, Dhanak D, Hingorani SR, Tuveson DA \& Thompson CB 2005 ATP citrate lyase inhibition can suppress tumor cell growth. Cancer Cell 8 311-321. (doi:10.1016/j.ccr.2005.09.008)

Hawksworth D, Ravindranath L, Chen Y, Furusato B, Sesterhenn IA, McLeod DG, Srivastava S \& Petrovics G 2010 Overexpression of C-MYC oncogene in prostate cancer predicts biochemical recurrence. Prostate Cancer and Prostatic Diseases 13 311-315. (doi:10.1038/pcan.2010.31)

Hawley SA, Pan DA, Mustard KJ, Ross L, Bain J, Edelman AM, Frenguelli BG \& Hardie DG 2005 Calmodulin-dependent protein kinase kinase- $\beta$ is an alternative upstream kinase for AMP-activated protein kinase. Cell Metabolism 2 9-19. (doi:10.1016/j.cmet.2005.05.009)

Heemers H, Vanderhoydonc F, Roskams T, Shechter I, Heyns W, Verhoeven G \& Swinnen JV 2003 Androgens stimulate coordinated lipogenic gene expression in normal target tissues in vivo. Molecular and Cellular Endocrinology 205 21-31. (doi:10.1016/\$0303-7207(03)00205-3)

Hensley CT, Wasti AT \& DeBerardinis RJ 2013 Glutamine and cancer: cell biology, physiology, and clinical opportunities. Journal of Clinical Investigation 123 3678-3684. (doi:10.1172/JCI69600)

Higa A, Mulot A, Delom F, Bouchecareilh M, Nguyen DT, Boismenu D, Wise MJ \& Chevet E 2011 Role of pro-oncogenic protein disulfide isomerase (PDI) family member anterior gradient 2 (AGR2) in the control of endoplasmic reticulum homeostasis. Journal of Biological Chemistry 286 44855-44868. (doi:10.1074/jbc.M111.275529)

Hollstein M, Sidransky D, Vogelstein B \& Harris CC 1991 p53 mutations in human cancers. Science 253 49-53. (doi:10.1126/science.1905840)

Hsu PP \& Sabatini DM 2008 Cancer cell metabolism: Warburg and beyond. Cell 134 703-707. (doi:10.1016/j.cell.2008.08.021)

Hu W, Zhang C, Wu R, Sun Y, Levine A \& Feng Z 2010 Glutaminase 2, a novel p53 target gene regulating energy metabolism and antioxidant function. PNAS 107 7455-7460. (doi:10.1073/pnas.1001006107)

Itkonen HM, Minner S, Guldvik IJ, Sandmann MJ, Tsourlakis MC, Berge V, Svindland A, Schlomm T \& Mills IG 2013 O-GlcNAc transferase integrates metabolic pathways to regulate the stability of c-MYC in human prostate cancer cells. Cancer Research 73 5277-5287. (doi:10.1158/0008-5472.CAN-13-0549)

Jentzmik F, Stephan C, Miller K, Schrader M, Erbersdobler A, Kristiansen G, Lein M \& Jung K 2010 Sarcosine in urine after digital rectal examination fails as a marker in prostate cancer detection and identification of aggressive tumours. European Urology 58 12-18 (discussion 20-21). (doi:10.1016/j.eururo.2010.01.035)

Jiang P, Du W, Wang X, Mancuso A, Gao X, Wu M \& Yang X 2011 p53 regulates biosynthesis through direct inactivation of glucose-6phosphate dehydrogenase. Nature Cell Biology 13 310-316. (doi:10.1038/ncb2172)

Kandoth C, McLellan MD, Vandin F, Ye K, Niu B, Lu C, Xie M, Zhang Q McMichael JF, Wyczalkowski MA et al. 2013 Mutational landscape and significance across 12 major cancer types. Nature 502 333-339. (doi:10.1038/nature12634)

Kastan MB \& Berkovich E 2007 p53: a two-faced cancer gene. Nature Cell Biology 9 489-491. (doi:10.1038/ncb0507-489)

Kim JW, Zeller KI, Wang Y, Jegga AG, Aronow BJ, O’Donnell KA \& Dang CV 2004 Evaluation of myc E-box phylogenetic footprints in glycolytic genes by chromatin immunoprecipitation assays. Molecular and Cellular Biology 24 5923-5936. (doi:10.1128/MCB.24.13.5923-5936.2004)

Kokontis J, Takakura K, Hay N \& Liao S 1994 Increased androgen receptor activity and altered $c$-myc expression in prostate cancer cells after longterm androgen deprivation. Cancer Research 54 1566-1573.

Kusakabe T, Maeda M, Hoshi N, Sugino T, Watanabe K, Fukuda T \& Suzuki T 2000 Fatty acid synthase is expressed mainly in adult hormone-sensitive cells or cells with high lipid metabolism and in proliferating fetal cells. Journal of Histochemistry and Cytochemistry $\mathbf{4 8}$ 613-622. (doi:10.1177/002215540004800505)

Lamont KR \& Tindall DJ 2010 Androgen regulation of gene expression. Advances in Cancer Research 107 137-162. (doi:10.1016/S0065230X(10)07005-3)

Li S, Hu MG, Sun Y, Yoshioka N, Ibaragi S, Sheng J, Sun G, Kishimoto K \& Hu GF 2013 Angiogenin mediates androgen-stimulated prostate cancer growth and enables castration resistance. Molecular Cancer Research 11 1203-1214. (doi:10.1158/1541-7786.MCR-13-0072)

Lloyd MD, Darley DJ, Wierzbicki AS \& Threadgill MD $2008 \alpha$-MethylacylCoA racemase - an 'obscure' metabolic enzyme takes centre stage. FEBS Journal 275 1089-1102. (doi:10.1111/j.1742-4658.2008.06290.x)

Mainwaring WI \& Derry NS 1983 Enhanced transcription of rRNA genes by purified androgen receptor complexes in vitro. Journal of Steroid Biochemistry 19 101-108. (doi:10.1016/S0022-4731(83)80012-0)

Marberger H, Marberger E, Mann T \& Lutwak-Mann C 1962 Citric acid in human prostatic secretion and metastasizing cancer of prostate gland. BMJ 1 835-836. (doi:10.1136/bmj.1.5281.835)

Margel D, Urbach DR, Lipscombe LL, Bell CM, Kulkarni G, Austin PC \& Fleshner N 2013 Metformin use and all-cause and prostate cancerspecific mortality among men with diabetes. Journal of Clinical Oncology 31 3069-3075. (doi:10.1200/JCO.2012.46.7043)

Massie CE \& Mills IG 2012 Mapping protein-DNA interactions using ChIPsequencing. Methods in Molecular Biology 809 157-173. (doi:10.1007/ 978-1-61779-376-9_11)

Massie CE, Lynch A, Ramos-Montoya A, Boren J, Stark R, Fazli L, Warren A, Scott H, Madhu B, Sharma N et al. 2011 The androgen receptor fuels prostate cancer by regulating central metabolism and biosynthesis. EMBO Journal 30 2719-2733. (doi:10.1038/emboj.2011.158)

Migita T, Ruiz S, Fornari A, Fiorentino M, Priolo C, Zadra G, Inazuka F, Grisanzio C, Palescandolo E, Shin E et al. 2009 Fatty acid synthase: a metabolic enzyme and candidate oncogene in prostate cancer. Journal of the National Cancer Institute 101 519-532. (doi:10.1093/ jnci/djp030)

Mimura N, Fulciniti M, Gorgun G, Tai YT, Cirstea D, Santo L, Hu Y, Fabre C, Minami J, Ohguchi H et al. 2012 Blockade of XBP1 splicing by inhibition of IRE1 $\alpha$ is a promising therapeutic option in multiple myeloma. Blood 119 5772-5781. (doi:10.1182/blood-2011-07-366633)

Nikiforov MA, Chandriani S, O'Connell B, Petrenko O, Kotenko I, Beavis A, Sedivy JM \& Cole MD 2002 A functional screen for Myc-responsive genes reveals serine hydroxymethyltransferase, a major source of the one-carbon unit for cell metabolism. Molecular and Cellular Biology 22 5793-5800. (doi:10.1128/MCB.22.16.5793-5800.2002)

O'Connell BC, Cheung AF, Simkevich CP, Tam W, Ren X, Mateyak MK \& Sedivy JM 2003 A large scale genetic analysis of c-Myc-regulated gene expression patterns. Journal of Biological Chemistry 278 12563-12573. (doi:10.1074/jbc.M210462200)

Osthus RC, Shim H, Kim S, Li Q, Reddy R, Mukherjee M, Xu Y, Wonsey D, Lee LA \& Dang CV 2000 Deregulation of glucose transporter 1 and glycolytic gene expression by c-Myc. Journal of Biological Chemistry 275 21797-21800. (doi:10.1074/jbc.C000023200)

Ottaviani S, Brooke GN, O’Hanlon-Brown C, Waxman J, Ali S \& Buluwela L 2013 Characterisation of the androgen regulation of glycine $\mathrm{N}$-methyltransferase in prostate cancer cells. Journal of Molecular Endocrinology 51 301-312. (doi:10.1530/JME-13-0169)

Plass C, Pfister SM, Lindroth AM, Bogatyrova O, Claus R \& Lichter P 2013 Mutations in regulators of the epigenome and their connections to global chromatin patterns in cancer. Nature Reviews. Genetics 14 765-780. (doi:10.1038/nrg3554)

Pritchard CC \& Nelson PS 2008 Gene expression profiling in the developing prostate. Differentiation 76 624-640. (doi:10.1111/ j.1432-0436.2008.00274.x)

Rajan P, Dalgliesh C, Carling PJ, Buist T, Zhang C, Grellscheid SN, Armstrong K, Stockley J, Simillion C, Gaughan L et al. 2011 Identification of novel androgen-regulated pathways and mRNA isoforms through genome-wide exon-specific profiling of the LNCaP 
transcriptome. PLOS ONE 6 e29088. (doi:10.1371/journal.pone. 0029088)

Ranasinghe WK, Xiao L, Kovac S, Chang M, Michiels C, Bolton D, Shulkes A, Baldwin GS \& Patel O 2013 The role of hypoxia-inducible factor $1 \alpha$ in determining the properties of castrate-resistant prostate cancers. PLoS ONE 8 e54251. (doi:10.1371/journal.pone.0054251)

Rubin MA, Zhou M, Dhanasekaran SM, Varambally S, Barrette TR, Sanda MG, Pienta KJ, Ghosh D \& Chinnaiyan AM 2002 $\alpha$-Methylacyl coenzyme A racemase as a tissue biomarker for prostate cancer. Journal of the American Medical Association 287 1662-1670. (doi:10.1001/jama.287.13.1662)

Segawa T, Nau ME, Xu LL, Chilukuri RN, Makarem M, Zhang W, Petrovics G, Sesterhenn IA, McLeod DG, Moul JW et al. 2002 Androgen-induced expression of endoplasmic reticulum (ER) stress response genes in prostate cancer cells. Oncogene 21 8749-8758. (doi:10.1038/sj.onc.1205992)

Sharma NL, Massie CE, Ramos-Montoya A, Zecchini V, Scott HE, Lamb AD, MacArthur S, Stark R, Warren AY, Mills IG et al. 2013 The androgen receptor induces a distinct transcriptional program in castrationresistant prostate cancer in man. Cancer Cell 23 35-47. (doi:10.1016/ j.ccr.2012.11.010)

Shim H, Dolde C, Lewis BC, Wu CS, Dang G, Jungmann RA, Dalla-Favera R \& Dang CV 1997 c-Myc transactivation of $L D H-A$ : implications for tumor metabolism and growth. PNAS 94 6658-6663. (doi:10.1073/ pnas.94.13.6658)

Singh KK, Desouki MM, Franklin RB \& Costello LC 2006 Mitochondrial aconitase and citrate metabolism in malignant and nonmalignant human prostate tissues. Molecular Cancer 5 14. (doi:10.1186/1476-45985-14)

Slawson C, Copeland RJ \& Hart GW 2010 O-GlcNAc signaling: a metabolic link between diabetes and cancer? Trends in Biochemical Sciences 35 547-555. (doi:10.1016/j.tibs.2010.04.005)

Sreekumar A, Poisson LM, Rajendiran TM, Khan AP, Cao Q, Yu J, Laxman B, Mehra R, Lonigro RJ, Li Y et al. 2009 Metabolomic profiles delineate potential role for sarcosine in prostate cancer progression. Nature $\mathbf{4 5 7}$ 910-914. (doi:10.1038/nature07762)

Suh DH, Kim MK, Kim HS, Chung HH \& Song YS 2012 Unfolded protein response to autophagy as a promising druggable target for anticancer therapy. Annals of the New York Academy of Sciences $127120-32$. (doi:10.1111/j.1749-6632.2012.06739.x)

Swinnen JV, Esquenet M, Goossens K, Heyns W \& Verhoeven G 1997 Androgens stimulate fatty acid synthase in the human prostate cancer cell line LNCaP. Cancer Research 57 1086-1090.

Tan SS, Ahmad I, Bennett HL, Singh L, Nixon C, Seywright M, Barnetson RJ, Edwards J \& Leung HY 2011 GRP78 up-regulation is associated with androgen receptor status, Hsp70-Hsp90 client proteins and castrateresistant prostate cancer. Journal of Pathology 223 81-87. (doi:10.1002/ path.2795)

Thompson TC 2011 Turning reciprocal feedback regulation into combination therapy. Cancer Cell 19 697-699. (doi:10.1016/j.ccr. 2011.05.022)

Thompson TC, Park SH, Timme TL, Ren C, Eastham JA, Donehower LA, Bradley A, Kadmon D \& Yang G 1995 Loss of p53 function leads to metastasis in ras + myc-initiated mouse prostate cancer. Oncogene 10 869-879.

Tokumaru Y, Harden SV, Sun DI, Yamashita K, Epstein JI \& Sidransky D 2004 Optimal use of a panel of methylation markers with GSTP1 hypermethylation in the diagnosis of prostate adenocarcinoma.
Clinical Cancer Research 10 5518-5522. (doi:10.1158/1078-0432. CCR-04-0108)

Tokumitsu H, Inuzuka H, Ishikawa Y, Ikeda M, Saji I \& Kobayashi R 2002 STO-609, a specific inhibitor of the $\mathrm{Ca}^{2+} /$ calmodulin-dependent protein kinase kinase. Journal of Biological Chemistry 277 15813-15818. (doi:10.1074/jbc.M201075200)

Towler MC \& Hardie DG 2007 AMP-activated protein kinase in metabolic control and insulin signaling. Circulation Research 100 328-341. (doi:10.1161/01.RES.0000256090.42690.05)

Vander Heiden MG, Cantley LC \& Thompson CB 2009 Understanding the Warburg effect: the metabolic requirements of cell proliferation. Science 324 1029-1033. (doi:10.1126/science.1160809)

Vousden KH 2010 Alternative fuel - another role for p53 in the regulation of metabolism. PNAS 107 7117-7118. (doi:10.1073/pnas.1002656107)

Wagner C \& Luka Z 2011 Sarcosine, folate metabolism and prostate cancer - is there a link? Journal of Urology 185 385-386. (doi:10.1016/j.juro. 2010.11.019)

Wang YC, Tang FY, Chen SY, Chen YM \& Chiang EP 2011 Glycine-N methyltransferase expression in HepG2 cells is involved in methyl group homeostasis by regulating transmethylation kinetics and DNA methylation. Journal of Nutrition 141 777-782. (doi:10.3945/jn.110.135954)

Warburg O, Wind F \& Negelein E 1927 The metabolism of tumors in the body. Journal of General Physiology 8 519-530. (doi:10.1085/jgp.8.6.519)

Wayner EA, Quek SI, Ahmad R, Ho ME, Loprieno MA, Zhou Y, Ellis WJ, True LD \& Liu AY 2012 Development of an ELISA to detect the secreted prostate cancer biomarker AGR2 in voided urine. Prostate $\mathbf{7 2}$ 1023-1034. (doi:10.1002/pros.21508)

Wellen KE, Hatzivassiliou G, Sachdeva UM, Bui TV, Cross JR \& Thompson CB 2009 ATP-citrate lyase links cellular metabolism to histone acetylation. Science 324 1076-1080. (doi:10.1126/science.1164097)

Wise DR, DeBerardinis RJ, Mancuso A, Sayed N, Zhang XY, Pfeiffer HK, Nissim I, Daikhin E, Yudkoff M, McMahon SB et al. 2008 Myc regulates a transcriptional program that stimulates mitochondrial glutaminolysis and leads to glutamine addiction. PNAS 105 18782-18787. (doi:10.1073/pnas.0810199105)

Wu Y, Chhipa RR, Cheng J, Zhang H, Mohler JL \& Ip C 2010 Androgen receptor-mTOR crosstalk is regulated by testosterone availability: implication for prostate cancer cell survival. Anticancer Research 30 3895-3901.

Wu D, Zhang C, Shen Y, Nephew KP \& Wang Q 2011 Androgen receptordriven chromatin looping in prostate cancer. Trends in Endocrinology and Metabolism 22 474-480. (doi:10.1016/j.tem.2011.07.006)

Yuneva M, Zamboni N, Oefner P, Sachidanandam R \& Lazebnik Y 2007 Deficiency in glutamine but not glucose induces MYC-dependent apoptosis in human cells. Journal of Cell Biology 178 93-105. (doi:10.1083/jcb.200703099)

Yuneva MO, Fan TW, Allen TD, Higashi RM, Ferraris DV, Tsukamoto T, Mates JM, Alonso FJ, Wang C, Seo Y et al. 2012 The metabolic profile of tumors depends on both the responsible genetic lesion and tissue type. Cell Metabolism 15 157-170. (doi:10.1016/j.cmet.2011.12.015)

Zaidi N, Swinnen JV \& Smans K 2012 ATP-citrate lyase: a key player in cancer metabolism. Cancer Research 72 3709-3714. (doi:10.1158/00085472.CAN-11-4112)

Zawacka-Pankau J, Grinkevich VV, Hunten S, Nikulenkov F, Gluch A, Li H, Enge M, Kel A \& Selivanova G 2011 Inhibition of glycolytic enzymes mediated by pharmacologically activated p53: targeting Warburg effect to fight cancer. Journal of Biological Chemistry $28641600-41615$. (doi:10.1074/jbc.M111.240812)

Received in final form 19 January 2014

Accepted 4 February 2014

Made available online as an Accepted Preprint

4 February 2014 http://erc.endocrinology-journals.org DOI: 10.1530/ERC-13-0515
(C) 2014 Society for Endocrinology Printed in Great Britain 